\title{
ethic@

\section{VIRTUE-BASED APPROACHES TO PROFESSIONAL ETHICS: A PLEA FOR MORE RIGOROUS USE OF EMPIRICAL SCIENCE}

\author{
GEORG SPIELTHENNER ${ }^{1}$ \\ (University of Dar es Salaam, Tanzania)
}

\begin{abstract}
Until recently, the method of professional ethics has been largely principle-based. But the failure of this approach to take into sufficient account the character of professionals has led to a revival of virtue ethics. The kind of professional virtue ethics that I am concerned with in this paper is teleological in that it relates the virtues of a profession to the ends of this profession. My aim is to show how empirical research can (in addition to philosophical inquiry) be used to develop virtue-based accounts of professional ethics, and that such empirically well-informed approaches are more convincing than traditional kinds of professional virtue ethics. The paper is divided into four sections. In the first, I outline the structure of a teleological approach to virtue ethics. In Section 2, I show that empirical research can play an essential role in professional ethics by emphasizing the difference between conceptual and empirical matters. Section 3 demonstrates the relevance of virtues in professional life; and the last section is concerned with some metaethical issues that are raised by a teleological account of professional virtues.
\end{abstract}

Keywords: Empirical ethics; professional ethics; professional virtues; science-based ethics; teleological virtue theory; virtue ethics

This article concerns itself with the application of virtue theory to professional ethics - that is, in short, to the ethics of professionals who are members of a particular profession such as medicine, law, teaching, or social work. Until recently, professional ethics was largely principle-based and virtues were deemphasized. Ethical conduct of professionals was commonly portrayed as consisting in adherence to ethical codes of conduct that had been adopted by professional associations. But critics have pointed out the limitations of this approach, e.g., the abstract nature and rigidity of principles and their failure to capture the richness and complexity of moral life. It is now widely acknowledged that not everything that is important in professional life can be captured by codes of conduct and that professionalism goes beyond ethical principles. This has led to an attempt to enrich principle-based ethics by including virtues to professional ethics. 
There is, however, a great variety of virtue theories, which differ both in terms of their aims and how they define the virtues (see Swanton 2013, for discussion). The most often employed approach to professional virtue ethics is the neo-Aristotelian type, according to which virtues are grounded in a purpose or end (telos). ${ }^{2}$ In Aristotle's ethics, this is the end of human beings; and in a neo-Aristotelian version of professional ethics, it is the end of a profession. That is to say, the kind of professional ethics that I am concerned with in this paper is teleological (but not consequentialist) in that it relates the virtues of a profession to the end of this profession. It is this end which gives content to professional virtues and on the basis of which they will be justified. That is, on such an account, professional virtues are essentially end-directed or teleological.

Some theories of neo-Aristotelian virtue ethics are rival accounts to principle-based ethical theories, holding that virtue ethics should replace other theories of normative ethics (in particular, consequentialist and deontological theories). But on the present account, virtues are only a supplementary component of a comprehensive theory of professional ethics, ${ }^{3}$ which would also include a theory of right action. ${ }^{4}$ That is, in this paper I do not aim to provide a complete picture of professional ethics.

As already noted, Aristotelian accounts of professional ethics have also been proposed by other authors. But these writers rely almost exclusively on their personal opinion and on everyday observations when they make claims about professional virtues (e.g., that virtues determine action or that they can be taught). Social scientists have repeatedly critiqued this method. They rightly hold that ethicists ought to place more emphasis on scientific evidence, and argue that by not taking empirical research seriously, ethics has lost much of its relevance (e.g., Hedgecoe 2004).

Against this background, the aim of this article is now simple to state. My main purpose is to show how empirical research can (in addition to philosophical inquiry) be used to develop virtue-based accounts of professional ethics, and that such empirically well-informed approaches are more convincing than traditional kinds of professional virtue ethics. In order to achieve this, the paper is organized as follows: In the first section, I outline the structure of a teleological approach to virtue ethics. In Section 2, I demonstrate that empirical research can play a vital role in professional ethics by emphasizing the difference between conceptual and empirical matters. The third section shows the relevance of virtues in professional life, and the last section is concerned with some metaethical issues that are raised by a teleological account of virtue ethics. 


\section{The structure of a virtue-based ethics}

The concept of virtue (and vice, but I will not mention vices every time I mention virtues) originated (at least in the Western world) in ancient Greek philosophy. The Greek word aretē, translated by Roman scholars into the Latin word virtus, from which the English 'virtue' derives, means roughly excellence. 'Virtue', therefore, refers to an excellence of its kind. But what kind is this? Although there are many rival conceptions of virtues, theorists widely agree that virtues are excellent traits of character. It is neither clear what traits are nor what a character is, ${ }^{5}$ but since there is no space here for an explication of these concepts, I must confine myself to a rough explanation. In short, traits of character are relatively stable and enduring psychological dispositions or tendencies to act in characteristic ways. Traits must therefore be distinguished from abilities, skills, talents, and a person's temperament. Since virtues are excellent traits of character, they are dispositions to act well (where what counts as acting well depends on the ethical conception that underlies a virtue theory).

As I have already mentioned, on the Aristotelian conception of ethics, virtues are needed to achieve our purpose as human beings (i.e., to live a flourishing life). By applying this conception to the realm of professional ethics, we get a teleological framework for a virtue-based account of professional ethics. On this account, professional virtues are grounded on the end of a profession. Just as Aristotle's virtues are derived from an (assumed) end of human beings, so are professional virtues those character traits which a professional needs for serving the end of his profession. (I will often omit the qualifier "professional" for the sake of brevity.) Calmness is arguably a virtue of airline pilots because it is needed when dealing with challenging weather conditions (being panicky would be a vice), and compassion is a virtue of doctors if this trait is needed to serve the goal of the medical profession well.

It is obvious that an adequate teleological theory of virtues must provide a defensible account of the goals specific to a profession. Pellegrino and Thomasma (1993) have sketched such an account for medicine. They hold that the medical profession has a variety of ends including the restoration or improvement of physical and mental health; Oakley and Cocking $(2001,75)$ regard achieving justice as the central goal of lawyering; Banks and Gallagher (2009) argue that minimizing suffering and distress is one of the purposes of the nursing profession. The growth of the personality of students has been 
proposed as the end of the teaching profession; and some hold that social welfare is the characteristic end of social work.

While it is plausible that at least the classical professions (e.g., medicine, law, education) have inherent ends (or service ideals), ${ }^{6}$ it must be admitted that the notion of a profession's end is less clear than one might wish. Different accounts of professional goals have been put forward, but both the nature of professions and their ends are contested (see Jansen 2000). In particular, professions can have several ends, which may not be equally important, as Banks and Gallagher (2009) have argued with regard to social work (see also Sockett 2009). These ends also seem to be relative to specific cultures. For example, the purposes of the teaching profession in an authoritarian society will differ from its goals in a democratic society. In addition, conceptions of professional goals can change over time. Professions do not have ends fixed for all time as Pellegrino and Thomasma (1993) have argued with reference to medicine. Furthermore, modern professionals occupy multiple roles. For example, a doctor may provide care, teach students, conduct research, and have administrative duties; and these diverse roles may require different virtues. Complicating matters still further, these roles are changing. For example, the role of teachers has changed from providers of information to facilitators in the learning process (see Szücs 2009); and while, in traditional nursing, a nurse was often viewed as the "handmaiden" of the physician, the role of nurses is now considered as one of advocacy for patients (see Beauchamp and Childress 2009).

But I think these problems are not insurmountable and are outweighed by the strengths of a teleological account, of which the following are particularly important. First, such an account offers a clear way of identifying virtues. Which character traits are virtues is determined by looking at what sorts of traits help professionals to meet the goals of their profession. In contradistinction to other types of virtue ethics where the identification of virtues is largely arbitrary (see Hursthouse 1991), the proposed teleological account can rely on empirical research to find out what traits are virtues of a certain profession. Knowing whether the telos of a profession requires a professional to be, say, assertive or compassionate becomes an empirical issue. Second, a teleological framework gives a clear answer to the question why some traits are virtues. That is, it provides a clear approach to justifying virtues. Virtue ethical theories often include lists of alleged virtues that only reflect the preferences of the theorists and are commonly taken from traditional virtue accounts (in particular from Aristotle's Nicomachean Ethics). This 
makes the assertion that certain traits are virtues rather arbitrary. But on the account presented here, the claim that a trait is a virtue can be justified by showing that it is needed for serving the (current) goals of a profession; and the evidence for this can be provided by empirical research.

\section{The conceptual and the empirical}

Virtue ethical accounts that take scientific research seriously must clearly distinguish between conceptual and empirical issues. In general, conceptual questions are prior to matters of fact; and any empirical inquiry about virtues and their effects that proceeds from a confused conceptual background is likely to be misdirected and will not yield satisfactory results. When we want to know whether humility is a virtue we must keep separate the conceptual questions 'What is a virtue?' and 'What is humility?' from the empirical question whether humility is a virtue. This empirical question can only be answered after we have answered the conceptual questions. Ethicists commonly confound conceptual and empirical issues. Let a simple example suffice to illustrate this. Beauchamp and Childress $(2009,38)$ hold that the virtue of compassion involves a regard for another's welfare (which is a conceptual claim about compassion and presupposes that compassion is a virtue), and they state that physicians who do not express compassion often fail to provide what patients most need (which is an empirical claim). But they neither provide definitions of the concepts involved, nor do they back up their empirical claim with real facts and data. And this is not an isolated case or exception. Authors frequently make claims about virtues that do not adequately represent contemporary scientific research but rather reflect the researchers' personal views and opinions (see, e.g., Driver 2001; Pellegrino 2002). ${ }^{7}$ While I hold that virtue ethics should be based on current scientific research (mainly personality psychology), I don't want to give the impression that I regard the knowledge of experienced professionals as irrelevant. On the contrary, the views of experienced teachers can provide valuable information about qualities of good teachers. But they should be tested in scientific studies because they may be biased. The point of this section is to provide clear definitions of key concepts and to show how scientific research can be used to improve the quality of virtue theories.

1. Let me begin with a clarification of the concept professional virtue, which is obviously central to any virtue-based theory of professional ethics. As already mentioned, on the account presented here, professional virtues are traits of character (or personality) 
that help a professional to serve a profession's purpose(s) well. We can put this succinctly by defining virtues as follows:

D1: A trait is a professional virtue if and only if a professional needs it (to at least some minimal degree) to serve the end(s) of the profession well.

A few words of explanation about some requirements of this definition will be helpful. By saying that a trait is needed, I do not mean that it is a necessary condition (in the strict sense of the term) for serving a profession well. I hold the weaker view that virtues are favourably relevant to the attainment of a profession's ends by making it more likely that a professional serves these ends well. The phrase, 'to at least some minimal degree' has been included because having a virtue is a matter of degree, and a trait like integrity can be a virtue even if a professional does not exemplify it to its fullest extent. The definition is a precising definition. That is, it is intended to make a vague everyday notion more exact without assigning it a completely new meaning. The definition has the logical form of a so-called biconditional (or equivalence), which is important for deriving several corollaries (see below).

That virtues are needed to serve the end of a profession is true by definition. There is no need for empirical research to confirm this. But the definition does not allow us to determine whether a certain trait is a virtue. For example, if we want to know whether meticulousness is a virtue of musicians, we first need to clarify the concept meticulousness and then find out whether this trait is needed to serve the musical profession well. This will require some sort of scientific research if we want to avoid subjectivity. That is, a satisfying answer to the question whether a trait is a virtue requires a combination of the conceptual and the empirical.

2. Let me turn now to the concept of a good professional. It is related to the notion of professional virtues because these virtues are characteristic features of good professionals. They enable a professional to be good qua professional. Good professionals possess and exercise professional virtues. We speak of a good lawyer, teacher, or engineer, and what we mean by this is that they are good at their respective profession. A good general is good as a general (but not necessarily as a human being). He is good at those activities, the skilful performance of which constitutes the excellence of generals (von Wright 1963, 33). The idea that a good professional is good at some activity can be made more exact by the following definition:

D2: A person is a good professional if and only if he or she serves the end(s) of a 
profession well.

If, for example, a teacher is good qua teacher he or she will serve the ends of the teaching profession well. As I have previously noted, authors tend to rely on their personal experience about such good-making qualities (claiming, e.g., that a good teacher must have the traits of patience, self-control, or fairness), but what qualities a good professional must (or should) have is obviously a question that is best answered by doing empirical research. There are some investigations on this (see, e.g., Braunack-Mayer 2005), but most claims made by ethicists do not meet scientific standards of rigour.

3. I will now briefly discuss the notion of a bad professional because it is not immediately clear how to define it. One might suggest that, say, a bad nurse is one that poorly serves the ends of the nursing profession, which is to hold that the notions of good and bad professionals are related to one another as contraries. But this seems to be a mistake. Following von Wright (1963), we should rather say that to be a bad professional is to suffer a privation. The bad nurse is one that is not good at nursing. That is to say that the concepts of good and bad professionals are contradictorily, and not contrarily, opposed to one another. We can therefore define this notion as follows:

D3: A person is a bad professional if and only if he or she does not serve the end(s) of a profession well.

The bad (or poor) professional is the not-good professional, and conversely. A bad teacher does not teach the students well (but need not spoil them) and a bad doctor does not serve his patients' interests (which does not imply that he worsens their ailments). It goes without saying that the empirical issues here are analogous to those mentioned in the previous paragraph. That an irritable person will be a poor teacher may seem plausible, but whether this is really so and what effects (under what circumstances) this trait will have, can only be found out by careful empirical research.

4. There should be a conceptual relationship between the notions of professional virtue and good professional. After all, professional virtues are the qualities which a professional needs for serving the ends of his profession well, and according to Definition 2 , this is exactly what a good professional does. In other words, we expect that professional virtues are attributes essential to a good professional. We can obtain this result by deducing the following corollary:

C1: A professional virtue is a trait that a person needs to be a good professional. 
This corollary (i.e., immediate consequence) can be derived from Definition 1, together with the thesis that if a trait is needed to serve the end of a profession well then it is also needed for being a good professional (where 'needed' again means being favourably relevant). I think this thesis is quite plausible. Since the good professional has been defined as a person who serves the ends of a profession well, any trait that is needed for this will also be needed by a good professional. By using this thesis, the derivation of (C1) becomes straightforward: The two premises (1) 'A trait is a professional virtue if and only if a professional needs it (to at least some minimal degree) to serve the end(s) of the profession well' (D1); and (2) 'If a trait is needed to serve the end of a profession well then it is also needed for being a good professional' (thesis) entail C1, as anyone familiar with elementary logic can prove.

Even though this corollary has been established by means of logic, empirical research about it can lead to interesting results. This is so because if the conclusion of a valid argument is false then at least one of its premises must be false, too. That is to say, if empirical research shows that some professional virtues are not needed for being a good professional then (D1) or our thesis (or both) are not tenable. Scientists have sometimes claimed that empirical research should be used to test normative and conceptual claims (see Hedgecoe 2004). I have given here a simple example of how this can be done in a logically correct way. ${ }^{8}$

Virtue ethicists make numerous claims about virtues that are not conceptual truths (i.e., they are not derivable from the definition of virtue), but empirical statements. In the remainder of this section, I will briefly discuss some of them and argue that ethicists will do better if they base such claims on scientific research.

1. Ethicists frequently hold that virtues have motivational force (see Hursthouse 1999; Pellegrino and Thomasma 1993; 1996), and some make quite specific claims about motivational effects of virtues. For example, Annas (2015) holds that virtuous persons are motivationally unconflicted, i.e., they need not overcome reluctance. The virtuous person will do the virtuous thing "without internal struggle" (p. 96). It is obvious that such claims are empirical in nature and need to be backed up by evidence. There has been considerable scientific research effort towards the investigation of motivational effects of personality traits. But in which way, if any, traits cause or influence behaviour is still controversially discussed in personality psychology (see Matthews and Deary 1998). Some researchers hold that traits have strong action guiding effects, while others, called 
situationists, claim that character traits do not influence agents' behaviour in any way because it varies with situational variation. Most contemporary trait theorists subscribe to interactionism, which is the view that both person and situation, and their mutual interaction, are important (Matthews and Deary 1998, 48). Be that as it may, virtue ethicists should not speculate about the motivational impact of character traits but rely on empirical research, even if it is inconclusive.

2. Virtue ethicists also commonly claim that virtues cause emotions. They hold that these feelings include moral emotions such as regret or grief as reactions to what an agent has done; but they also hold that virtuous persons enjoy acting virtuously (Annas 2011, 69). These theorists may feel entitled to such claims because they often define virtues as dispositions to feel and act in certain ways (e.g., Annas 2015; MacIntyre 1985). But even if they include the concept of emotion in their definition of virtues (which may make the definition inadequate or purely stipulative), they are not entitled to hold, for example, that a generous person enjoys giving money to the needy or that a compassionate person will be upset when hearing of the plight of the homeless. Such claims go beyond any definition of virtue and are factual in nature. The investigation about what emotions a virtuous person experiences in response to something should therefore be left to the empirical sciences.

3. Other empirical claims made by virtue ethicists include the following: (i) They commonly hold that virtues are stable dispositions, which implies that they remain unaltered over time. Psychological research suggests, however, that this is not generally true. Some traits (e.g., conscientiousness) seem to be quite stable, while others (e.g., agreeableness) appear to be less stable (Matthews and Deary 1998, 54). (ii) Ethicists also tend to believe that virtues are consistent across situations. That is, a person who is honest behaves in an honest way in different situations (e.g., does not cheat in exams and does not evade taxes). This folk-psychological view is, however, not confirmed by contemporary personality research. (iii) Virtues can be differently composed into a whole, in which they interact. The result of this interaction will be different, depending on what virtues interact, and in which way they influence each other. Philosophers maintain that one virtue may temporarily be at war with another (MacIntyre 1985), and that some combinations may be destructive (Driver 2001). But the interaction of character traits and its effects is obviously an empirical matter that needs to be investigated by carefully designed experiments, and should therefore be left to trait psychologists. (iv) 
Furthermore, virtue ethicists hold that virtues benefit their possessor (see Hursthouse 1999), and some have claimed that professional virtues bring "professional satisfaction" (Harris 2008, 158). But they rely only on their personal observations and do not provide any scientific evidence for their convictions. (v) Ethicists also claim that virtues have cognitive effects in that they direct a person's thinking-e.g., cause a benevolent person to pay more attention to the plight of others. Even though current psychology cannot verify this far-reaching hypothesis, there is at least some research that seems to support it (Matthews and Deary 1998, 73).

To summarize, virtue ethics involves many conceptual and empirical issues. It is therefore important that ethicists clarify the concepts they employ and take empirical research seriously when they construct virtue theories.

\section{The relevance of virtues in professional life}

Much of recent work in virtue ethics, including virtue-based professional ethics, suffers from a lack of detail about how this ethical approach can be applied to issues of professional life. In this section, I briefly discuss the relevance of virtues to professional education, personnel recruitment and selection, and performance appraisal.

1. Authors in the field of nursing ethics recommend that schools of nursing add the teaching of virtues to their curriculum (see Sellman 1997; Smith and Godfrey 2002), or make the yet stronger claim that virtues relevant to nursing should be a requirement for admission of candidates to schools of nursing (Catlett and Lovan 2011). The main reason for this is that patients' dissatisfaction with nursing care has been shown to be partly due to nurses' poor traits of character (Chen and Hsu 2015), and it is hoped that character formation will improve the situation. Similarly, it has been recommended that teaching of virtues becomes a component of the training of professional psychologists (Jordan and Meara 1990); and other authors have suggested that virtues are taught in medical schools (e.g., Doukas 2003; Pellegrino and Thomasma 1993). The rationale for these recommendations is that good professional practice requires a set of personality traits that enable and motivate professionals to serve the ends of their profession well.

This raises the question of how virtues are acquired, and in particular, whether they can be taught and learned. Most philosophers follow Aristotle and hold that virtues are not innate but acquired (even though persons may be by nature more or less disposed towards various virtues). But there is no agreement about the nature of their acquisition. 
Some think that virtues can be taught and learned like skills (e.g., playing the piano), which is a view similar to Aristotle's position (Annas 2011). Others seem to be confident that virtues can be taught in courses in practical ethics (see Harris 2008; Pellegrino 2002).

It is clear that we are here once more faced with an empirical issue. The scientific literature on the acquisition of character traits suggests that both genetics and the environment contribute to traits. This implies that character traits have at least some biological basis (see Matthews and Deary 1998). In which way (if any) virtues can be taught is an issue which philosophers can and should leave to the educationists.

2. Since virtues seem essential to proper conduct of professionals, it has been suggested that they are used for selecting applicants to particular occupations. For example, most people would be reluctant to fly in an aeroplane that is piloted by a person with abnormally high sensation-seeking (a disposition to pursue excitement, take risks and seek thrills) and, in fact, some airlines use already tests to screen out would-be pilots who have traits considered to be inappropriate to airline pilots (see Matthews and Deary 1998). Some researchers are sceptical about the use of such tests, holding that they have large margins of error and are too easily psyched out (Pellegrino and Thomasma 1993). But research suggests that traits (e.g., conscientiousness) are relevant to decisions about personnel recruitment (see Salgado 1997). Personality measures are, therefore, now used in various professions, including medicine (see DeRosa 2006) and business sector organisations (e.g., integrity tests for predicting employee theft).

3. There is also a relationship between personality and general occupational performance. Evidence suggests that traits are correlated to performance criteria, and personality questionnaires are now widely used to assess job performance (see Kanfer et al. 1995). For example, in their comprehensive meta-analysis on integrity tests, Ones et al. (1993) have shown that such questionnaires "are substantial for predicting job performance and counterproductive behaviors on the job, such as theft, disciplinary problems, and absenteeism" (p. 679). That character traits are correlated to job performance is also suggested by the meta-analysis of Hurtz and Donovan (2000), who focussed on conscientiousness and found that it has a strong relation to overall job performance.

The research presented in this section indicates that professional virtues are not only an interesting subject for academic researchers, but have important applications to practical issues in professional life, too. 


\section{Some metaethical reflections on professional virtues}

Virtue ethical theories raise numerous metaethical issues-e.g., whether virtues are necessarily evaluative traits or whether they can be used for justifying our actions. This section is concerned with the main metaethical questions that are raised by teleological accounts of professional ethics.

1. Ethicists commonly hold that virtues are good traits of character. The question then arises what value they are supposed to have. The philosophical literature distinguishes between intrinsic and extrinsic values. If a thing is intrinsically good it is said to be good in itself or good for its own sake. If, on the other hand, a thing is extrinsically good then it gets the value from some other source. For example, if a thing is a means to something that is good, it is extrinsically good-more specifically, it is then said to be instrumentally good. ${ }^{9}$

Theorists frequently claim that virtues are intrinsically good (Annas 2011; Swanton 2003). This is, however, a controversial view because it entails that a trait like courage would be valuable even if it had no effects on its possessor's behaviour and even if it consistently led to immoral conduct. On the account presented in this paper, virtues have instrumental value (or disvalue). Let me explain. In professional ethics, it is generally assumed that the ends of a profession are good. Researchers hold that professions provide benefits to a society (e.g., health is provided by the medical profession and growth of the personality of students by the teaching profession). As we have seen, professional virtues are needed to serve these good ends. They are means by which professionals can attain the ends of their profession; and from this it follows that the value of these virtues is instrumental. ${ }^{10}$ In other words, the value of virtues is derivative, it stems from the good ends to which they are means.

I should mention here, however, that on a teleological conception, virtues are not necessarily good traits. If the ends are bad, the means to these ends are instrumentally bad. It is easily conceivable that someone regards the end of a profession as bad, in which case he will also regard the "virtues" of this profession as bad. For example, obedience to superiors is a quintessential virtue of military professionals. From the viewpoint of a pacifist, the ends of the military profession may be bad, which may render obedience to superiors an instrumental evil. 
2. Many theorists hold that evaluative sentences (e.g., 'It is good to be honest') are, strictly speaking, neither true nor false. If virtues are (usually) good traits the question arises whether virtue-statements admit of truth-values (i.e., are true or false). That is, are statements like 'Compassion is a virtue of doctors' true or false? To answer this question, let us briefly consider two different but related kinds of statements. I will argue that both of them admit of truth-values.

(i) The statement 'Assertiveness is a virtue of lawyers' is true if and only if assertiveness is a trait that is needed by lawyers to serve the ends of the legal profession well. This is a conceptual truth. In other words, the statement is true if assertiveness satisfies the definition of professional virtues (see D1 in Section 2). This shows that on my teleological account, virtue-statements are true or false. But we can only determine what truth-value they have by conducting empirical research. (ii) Statements about good professionals - e.g., 'Smith is a good teacher' —also admit of truth-values. The statement about Smith is true if he or she serves the ends of the teaching profession well. Any professional who satisfies the definition of good professionals (see Section 2) is, by definition, a good professional. It goes without saying that we can only know whether such statements are true by doing some sort of empirical research.

3. We often hold that a person has a certain virtue or vice-e.g., that Smith is an employee of the highest integrity or that Jones is corrupt. Since professional virtues are (normally) good traits, such statements commonly express value judgements. I will now explain why such virtue-statements nevertheless admit of truth-values.

A statement like 'Alfred is meticulous' can be purely descriptive (i.e., used only for conveying information without expressing any evaluation), in which case it is clearly true or false. But there is no doubt that in most contexts we also evaluate Alfred when we call him meticulous. That is to say, one and the same verbal expression can be used to perform different roles. In philosophy, concepts like honesty, courage, generosity, or cruelty have been called thick concepts because they are evaluative and have significant descriptive content (in contradistinction to so-called thin concepts like ought or good). They are merging the descriptive with the evaluative. By claiming that Peter is cruel, we are making a descriptive statement (saying, roughly, that he has a disposition of intentionally causing pain to people or animals), but (in most contexts) we also express a negative attitude towards him—that is, we evaluate him negatively. Whether or not our statement 
about Peter is true depends on its descriptive content only. It is true if Peter really has the disposition of intentionally causing pain.

To sum, when we state that a person has a professional virtue (or vice), we may only make a descriptive statement. But on most occasions we do both, we make a factual statement and express a value judgement. That is to say, we make hybrid statements. Appreciating this fact about evaluative language is important to understand virtue-based reasoning, to which I turn now.

4. Virtue ethicists commonly claim that virtues provide reasons for action (even though they do not always distinguish between motivating and justifying reasons, see Hursthouse 1999). On this view, we can argue 'I should return the money because this is the honest thing to do', where 'this is the honest thing to do' provides a justification for returning the money. Such virtue-based reasoning is, however, more complex than it may appear at first sight. In what follows, I will briefly explain when it is logically correct and when it is fallacious.

Let us start with a simple example. A professional may argue: 'I should support my organization's interests because this is required by loyalty'. In this example, the sentence 'I should support my organization's interests' is the normative conclusion, which has been justified by reference to the virtue of loyalty. Such an inferential justification is, however, only possible if loyalty is a hybrid (and therefore evaluative) concept. To explain why this is so, I must say a few words about the so-called is-ought problem. According to a widely accepted view, called Hume's Law after the eighteenth-century philosopher David Hume, normative conclusions can only be validly inferred if at least one of the premises is normative or evaluative. According to Hume's Law, we are making a serious logical mistake it we try to infer normative conclusions from only descriptive premises. Hume's thesis asserts that no number of stated facts logically entail what we should do. Returning to our example, the normative conclusion 'I should support my organization's interests' can therefore only be justified if 'this is required by loyalty' is an evaluative statement, which is only the case if loyalty is a hybrid concept.

As I have mentioned above, virtue concepts can be purely descriptive. If loyalty is a descriptive concept the sentence 'Loyalty requires supporting one's organization' expresses a purely descriptive statement, which cannot be used to justify the normative claim that I should support my organization's interests. The reason for this is the logical gap between the descriptive and the evaluative, on which Hume's Law is based. 
To sum up this brief discussion of a complex issue, virtue-based reasoning to a normative conclusion is only logically correct if the virtues that have been invoked in order to establish the conclusion are hybrid concepts because this implies that at least one of the premises used as reasons for the conclusion is an evaluative statement.

The result of this investigation may be summarized as follows. Virtues have a genuine role to play in professional ethics because virtue ethical accounts can supplement the use of ethical principles, which is still predominant in this branch of practical ethics. A teleological approach to a virtue-based ethics seems to offer the most promising way of dealing with professional virtues. It can be based on empirical evidence; and by relying on scientific research, it ensures that professional virtues are investigated in a nonarbitrary way, which guarantees more objectivity in ethical research. 


\title{
Notes
}

${ }^{1}$ In memoriam. Georg Spielthenner was Professor of Philosophy at the University of Zambia and the University of Dar es Salaam, Dar es Salaam, Tanzania. E-mail: georg_spielthenner@yahoo.de

${ }^{2}$ See, for example, the account of Banks and Gallagher (2009), who discuss virtue ethics from the viewpoint of nursing and social work; the virtue theories of medical ethics by Pellegrino and Thomasma (1993) or Oakley and Cocking (2001); Stovall's (2011) approach to engineering ethics; and the discussion of virtues in bioethics by Beauchamp and Childress (2009).

${ }^{3}$ Since practical ethics (of which professional ethics is a branch) is now commonly regarded as a quandary ethics that should help us to make difficult moral choices, virtue ethics has often been criticised as inappropriate for practical ethics. Its critics hold that virtue ethics provides only an insufficient guide to action and that it is only a weak substitute to consequentialist or deontological ethical theories because it focuses on the character of agents rather than on answering the question "What ought I to do?" (see, e.g., Beauchamp and Childress 2009; Louden 1984). Be that as it may, a supplementary account of virtue ethics is not open to this criticism.

${ }^{4}$ Virtue ethicists have suggested a variety of theories of right action. Hursthouse's (1991, 225) definition that "an act is right if and only if it is what a virtuous agent would do in the circumstances" (see also Hursthouse 1999, 28) has, by some, been thought canonical; but it has been criticised as circular by others (e.g., Pellegrino 1995). More recently, other definitions have been proposed (see Swanton 2003; van Zyl 2013), which cannot be discussed here. On the teleological account presented in this paper, a definition of right action should not depend on the notion of virtue. Right actions should rather be defined in terms of the ends of a profession. Following Stovall (2011), one can (tentatively) define that a professional does the right thing (qua professional) if his action furthers the aims of that profession. An elucidation and defence of this definition goes, however, beyond the scope of this paper.

\begin{abstract}
${ }^{5}$ In particular, the concept of character is elusive. There is a vast literature on personality traits, which is a key concept of modern psychology (see e.g., Matthews and Deary 1998), but character plays only a negligible role in contemporary psychology. One reason for this is that 'character' is a term that is frequently used as a synonym of 'personality' (or as an aspect of it), and that it is, therefore, difficult to distinguish between personality traits and character traits. Some authors have tried to draw a distinction between character and personality (e.g., Miller 2014), but, I am afraid to say, their attempts are not convincing. I think it is fair to say that there is no clear demarcation between the concepts of character and personality. In the remainder of this article, I will, therefore, refer to research in personality psychology to substantiate my claim that empirical research is important for virtue ethics.
\end{abstract}

${ }^{6}$ Indeed, on some conceptions of a profession this is a conceptual truth. On a narrow viewpoint, professions always promote some goals. That is, there cannot be professions that do not have an inherent end (see Airaksinen 2012). But on a broader everyday conception, any type of work that needs special training or a particular skill can be called a profession, and their structure does not necessarily include a precisely defined purpose or service ideal (see Banks and Gallagher 2009, 13-4). A discussion about problems of defining professions can be found in Meyers (2013).

${ }^{7}$ To be fair, I should mention that some authors do include some empirical research in their virtue ethical accounts (e.g., Banks and Gallagher 2009; Chen and Hsu 2015; Miller 2014), but they are only a small minority.

${ }^{8}$ We could derive numerous other corollaries from our definitions and C1-e.g., C2: A bad professional does not serve the end of his profession well; C3: If a professional serves his profession well, then he is not a bad professional; $\mathrm{C} 4$ : If a trait is not needed by a good professional then it is also not needed to serve the end of a profession well; or C5: A good professional has at least some of the virtues. But to avoid tedium, I have only briefly discussed one of these corollaries.

${ }^{9}$ For the sake of brevity, I am here glossing over various distinctions_e.g., between being good in itself and being valued for its own sake (see Korsgaard 1983). 
10 That virtues are instrumentally good does, however, not exclude that they are also intrinsically good because these notions are not mutually exclusive. For instance, one can hold that traits like honesty or compassion are both good as means and good in themselves. My account does not rule out this possibility, but it is an issue that I cannot pursue here. 


\section{References}

Airaksinen, T. (2012). Professional ethics. In R. Chadwick (ed.). Encyclopedia of applied ethics, vol. 3, (pp. 612-623). Amsterdam: Elsevier.

Annas, J. (2011). Intelligent virtue. Oxford: Oxford University Press. (2015). Virtue, skill and vice. Ethics \& Politics, XVII, 94-106.

Banks, S. and Gallagher, A. (2009). Ethics in professional life: Virtues for health and social care. New York: Palgrave Macmillan.

Beauchamp, T. L. and Childress, J. F. (2009). Principles of biomedical ethics (6th ed.). New York: Oxford University Press.

Braunack-Mayer, A. (2005). What makes a good GP? An empirical perspective on virtue in general practice. Journal of Medical Ethics, 31, 82-87.

Catlett, S. and Lovan, S. R. (2011). Being a good nurse and doing the right thing: A replication study. Nursing Ethics, 18, 54-63.

Chen, S. Y. and Hsu, H. C. (2015). Nurses' reflections on good nurse traits: Implications for improving care quality. Nursing Ethics, 22, 790-802.

DeRosa, G. R. (2006). Professionalism and virtues. Clinical Orthopaedics and Related Research, 449, 28-33.

Doukas, D. J. (2003). Where is the virtue in professionalism? Cambridge Quarterly of Healthcare Ethics, 12, 147-154.

Driver, J. (2001). Uneasy virtue. Cambridge: Cambridge University Press.

Harris, C. E. (2008). The good engineer: Giving virtue its due in engineering ethics. Science and Engineering Ethics, 14, 153-164.

Hedgecoe, A. M. (2004). Critical bioethics: Beyond the social science critique of applied ethics. Bioethics, 18, 120-143.

Hursthouse, R. (1991). Virtue theory and abortion. Philosophy \& Public Affairs, 20, 223 246.

(1999). On virtue ethics. Oxford: Oxford University Press.

Hurtz, G. M. and Donovan, J. J. (2000). Personality and job performance: The Big Five revisited. Journal of Applied Psychology, 85, 869-879.

Jansen, L. A. (2000). The virtues in their place: Virtue ethics in medicine. Theoretical Medicine 21, 261-276. 
Jordan, A. E. and Meara, N. M. (1990). Ethics and the professional practice of psychologists: The role of virtues and principles. Professional Psychology: Research and Practice, 21, 107-114.

Kanfer, R., Ackerman, P. L., Murtha, T., and Goff, M. (1995). Personality and intelligence in industrial and organizational psychology. In D. H. Saklofske and M. Zeidner (eds.). International handbook of personality and intelligence. New York: Plenum.

Korsgaard, C. M. (1983). Two distinctions in goodness. The Philosophical Review, 92, 169-97.

Louden, R. B. (1984). On some vices of virtue ethics. American Philosophical Quarterly, 21, 227-236.

MacIntyre, A. (1985). After virtue: A study in moral theory (2nd ed.). London: Duckworth.

Matthews, G. and Deary, I. J. (1998). Personality traits. Cambridge: Cambridge University Press.

Meyers, C. (2013). Professional ethics. In H. LaFollette (ed.), The international encyclopedia of ethics, vol. 7, (pp. 4121-4234). Chichester: Wiley-Blackwell.

Miller, C. B. (2014). Character and moral psychology. Oxford: Oxford University Press. Oakley, J. and Cocking, D. (2001). Virtue ethics and professional roles. Cambridge: Cambridge University Press.

Ones, D. S., Viswesvaran, C., and Schmidt, F. L. (1993). Comprehensive meta-analysis of integrity test validities: Findings and implications for personnel selection and theories of job performance. Journal of Applied Psychology, 78, 679-703.

Pellegrino, E. D. (1995). Toward a virtue-based normative ethics for the health professions. Kennedy Institute of Ethics Journal, 5, 253-277.

(2002). Professionalism, profession and the virtues of the good physician. The Mount Sinai Journal of Medicine, 69, 378-384.

Pellegrino, E. D. and Thomasma, D. C. (1993). The virtues in medical practice. New York: Oxford University Press.

Georgetown University Press.

Salgado, J. F. (1997). The five factor model of personality and job performance in the European Community. Journal of Applied Psychology, 82, 30-43.

Sellman, D. (1997). The virtues in the moral education of nurses: Florence Nightingale revisited. Nursing Ethics, 4, 3-11. 
Smith, K. V. and Godfrey, N. S. (2002). Being a good nurse and doing the right thing: A qualitative study. Nursing Ethics, 9, 301-312.

Sockett, H. (2009). Dispositions as virtues: The complexity of the construct. Journal of Teacher Education, 60, 291-303.

Stovall, P. (2011). Professional virtue and professional self-awareness: A case study in engineering ethics. Science and Engineering Ethics, 17, 109-132.

Swanton, C. (2003). Virtue ethics: A pluralistic view. Oxford: Oxford University Press.

(2013). The definition of virtue ethics. In D. C. Russell (ed.). The Cambridge companion to virtue ethics (pp. 315-338). Cambridge: Cambridge University Press.

Szücs, É. U. (2009). The role of teachers in the 21 st century. Revue Internationale, 10, 18 .

Van Zyl, L. (2013). Virtue ethics and right action. In D. C. Russell (ed.). The Cambridge companion to virtue ethics (pp. 172-196). Cambridge: Cambridge University Press.

Von Wright, G. H. (1963). The varieties of goodness. London: Routledge \& Kegan Paul. 